\title{
Erratum to: The Molecular Detection of Corynespora Cassiicola on Cucumber by PCR Assay Using DNAman Software and NCBI
}

\author{
Weiqing Wang ${ }^{(凶)}$ \\ Beijing Vocational College of Agriculture, Beijing, China \\ weiqingfine@163.com
}

\section{Erratum to:}

\section{Chapter 26 in: D. Li and Z. Li (Eds.)}

Computer and Computing Technologies in Agriculture IX DOI: 10.1007/978-3-319-48354-2_26

The original version of the paper starting on p. 248 was revised. The affiliation of the author was corrected.

The updated original online version for this chapter can be found at DOI: 10.1007/978-3-319-48354-2_26 